\title{
OSA Rochester Section Optics Suitcase: a forty-minute middle school outreach program for the cost of a postage stamp
}

Stephen Jacobs, Leslie Gregg

Stephen D. Jacobs, Leslie L. Gregg, "OSA Rochester Section Optics Suitcase: a forty-minute middle school outreach program for the cost of a postage stamp," Proc. SPIE 9663, Eighth International Topical Meeting on Education and Training in Optics and Photonics, 96632B (6 October 2003); doi: $10.1117 / 12.2208523$

SPIE Event: Eighth International Topical Meeting on Education and Training in Optics and Photonics, 2003, Tucson, Arizona, United States 


\title{
OSA Rochester Section Optics Suitcase: A forty-minute middle school outreach program for the cost of a postage stamp
}

\author{
Stephen D. Jacobs and Leslie L. Gregg \\ University of Rochester, 240 East River Road, Rochester, New York 14623 \\ telephone: 585-275-2478; fax: 585-275-7225; e-mail: sjac@lle.rochester.edu
}

\begin{abstract}
The Rochester Section of the Optical Society of America offers a middle school outreach program called the Optics Suitcase. Contents include re-usable demos and give-away experiments that illustrate color in white light. Over 40 suitcases have been shipped, free of charge, to groups in the USA, Canada, Ireland, Germany, Australia and South Africa.

(C)2003 Optical Society of America

OCIS codes: (000.2060) Education; (330.1690) Color
\end{abstract}

\section{Summary}

Members of the Rochester Section of the Optical Society of America have conducted career awareness workshops for teachers and in-class presentations for middle school children since late 1999. Our strategy is to encourage optics professionals to go into the classroom, demonstrating to students that engineering can be fun and exciting. We offer potential speakers a written 14-page guide to giving a presentation (http://www.opticsexcellence.org/SJ TeamSite/index.html), and we equip them with 40 minutes of interactive hands-on material on careers in technology, contained in the Optics Suitcase. The Suitcase contains an array of reusable and give-away items that provide the presenter with an exciting means for introducing children to optical engineering as an attractive career choice. Careers in optics are emphasized by experiments with three-take-home theme packets that explore color in white light through diffraction, polarization, and liquid crystals. The Suitcase contains sufficient quantities of take-home theme packets to reach 75 middle school children and their families.

We provide our Optics Suitcase to organizations everywhere. All we require is a letter describing the organization and its intended activities. Refills are provided when requested, in exchange for follow-up information. To date over 40 Suitcases have been distributed, free of charge, to 21 states in the USA, and to Canada, Ireland, Germany, Australia and South Africa. In this poster paper we describe the program and provide samples of feedback from many of the thousands of students and dozens of presenters who have enjoyed the Suitcase over the past four years.

\section{References}

S. D. Jacobs “Take-Home Demo Excites Young People About Careers in Technology,” Opt. Photonics News, pp. 16-17 (July 2000).

S. D. Jacobs and L. L. Gregg, "Making Waves with the Optics Suitcase," Opt. Photonics News, pp. 12-14 (July 2002).

Eighth International Topical Meeting on Education and Training in Optics and Photonics,

edited by Barry L. Shoop, Grover Swartzlander Jr., Proc. of SPIE Vol. 9663, 96632B

(C) 2003 SPIE, OSA, ICO · doi: 10.1117/12.2208523

Proc. of SPIE Vol. 9663 96632B-1 